\title{
ANALYSIS OF IMMATURE PLATELET FRACTION AND MEAN PLATELET VOLUME IN ACUTE CORONARY SYNDROME PATIENT
}

\author{
Pratia Paramita, Asvin Nurulita, Ruland DN Pakasi \\ Department of Clinical Pathology, Faculty of Medicine, Hasanuddin University/Dr.Wahidin Sudirohusodo Hospital Makassar, Indonesia. E- \\ mail:pratiaparamita@gmail.com
}

\begin{abstract}
Platelets have played a central role in the pathogenesis of Acute Coronary Syndrome (ACS). Immature Platelet Fraction (IPF) is considered as a potential marker of the platelet activation process and platelet turnover. Immature platelets have a greater prothrombotic potential and aggregate more rapidly with collagen that will affect platelet hemostasis potential that may contribute. Therefore IPF is associated with the progression of coronary heart disease. Mean Platelet Volume (MPV) values reflect platelet activation. The general purpose of this study was to analyze the value of IMF and MPV in establishing the diagnosis and prognosis of ACS. A cross-sectional study was held in the clinical pathology laboratory of Dr. Wahidin Sudirohusodo Hospital Makassar during September-November 2016. Sixty-seven patients with ACS were involved with a distribution of 30 patients with STEMI (44.8\%), 30 patients NSTEMI (44.8\%), and 7 patients Unstable Angina Pectoris (UAP) (10.4\%). Subjects are mostly male (73.1\%) and young adult age (82.1\%). There was a significant difference in IPF value especially of STEMI group with a mean $3.1(p=0.004)$ and no significant difference of MPV value in ACS group. Pearson correlation test showed there was a positive correlation with weak strength of IPF and MPV values in ACS patients ( $p=0.02$, $r=0.388)$. There was a significant difference between IPF scores according to the GRACE score $(p=0.005)$. Increased IPF in STEMI group. The IPF score can be considered as a risk stratification of ACS patients replacing GRACE score. There was a positive correlation with a weak strength of IPF and MPV value in ACS patients.
\end{abstract}

Key words: Mean platelet volume, immature platelet fraction, GRACE score

\section{INTRODUCTION}

Acute Coronary Syndrome (ACS) is an emergency with clinical manifestations of chest discomfort or group of symptoms resulting from acute myocardial ischemia ranging from Unstable Angina Pectoris (UAP) to Acute Myocardial Infarction (AMI). Myocardial infarction consists of ST-Segment Elevation Myocardial Infarction (STEMI) and myocardial infarction without ST-Segment Elevation (NSTEMI/non ST-segment elevation myocardial infarction). The incidence of ACS increases every year and is the leading cause of death in the world including Indonesia., ${ }^{1,2}$ The presence of ST-segment elevation in the ECG reflects the total occlusion of the coronary arteries. In NSTEMI and UAP, the occlusion is partial. Both have similar clinical symptoms and pathophysiology but differin their degree of severity.

Platelets have a central role in the pathogenesis of ACS. Acute coronary syndrome results from platelet plaque in the coronary arteries. Mean Platelet Volume (MPV) is the average size of platelets in the blood and reflects platelet activation.
Reticulated platelet or Immature Platelet Fraction (IPF) is young platelets released into circulation and has potential as a marker of the platelet activation and turnover. ${ }^{2,3}$

A study conducted by Erik et al., in Denmark showed a significant increase IPF in ACS patients. Study conducted by Marie et al. in the Netherlands showed that IPF is a more sensitive and specific diagnostic marker earlier than MPV to evaluate platelet turnover in ACS patients and showed a positive correlation between MPV and IPF. Study conducted by Jose et al. in the United States showed that an increase in IPF within 24 hours indicates a poor prognosis, in spite of normal cardiac biomarkers and even if the patients did not meet the GRACE score risk factor. ${ }^{4}$

A study conducted by Chang et al., in China showed explained the association of MPV with heart disease, especially coronary heart disease. It is known that platelet activation and aggregation play a role in thrombus formation. A study conducted by Mumpuni in Indonesia stated that the increase in MPV as a predictor of major cardiovascular events in ACS. A study conducted by Eza et al., in Iran showed 
that MPV can be used for early detection of ACS and risk stratification when other cardiac biomarkers are normal. ${ }^{4}$ The general purpose of this study was to analyze the value of IMF and MPV in establishing the diagnosis and prognosis of ACS.

\section{METHODS}

It was a cross-sectional study on ACS patients from September to November 2016 in the Clinical Pathology Laboratory of Dr. Wahidin Sudirohusodo Hospital Makassar, involving 67 samples diagnosed with ACS. The study population was all patients with ACS in the Dr. Wahidin Sudirohusodo Hospital Makassar. The study sample included all medical record data of ACS patients and the results of routine hematology test at Dr. Wahidin Sudirohusodo Hospital Makassar.

The inclusion criteria were ACS patients diagnosed by the cardiologist. Acute coronary syndrome patients were excluded if there was a history of percutaneous coronary intervention, previous history of heart disease, history of antiplatelet therapy, and incomplete medical record data. Immature platelet fraction and MPV values were obtained from routine hematology tests using Sysmex XN-1000 hematology analyzer. This study was approved by the Health Research Ethical Committee of Hasanuddin University/Wahidin Sudirohusodo Hospital Makassar with number UH17080547.

\section{RESULTS AND DISCUSSION}

A total of 67 ACS patient data were obtained, consisted of 30 STEMI, 30 NSTEMI, and 7 UAP patients can be seen in Table 1.

The sex distribution in this study was consistent with the results of a study conducted by Ongkowijaya et al., in Surabaya, which reported that ACS was more common in male (73.1\%) than female (26.9\%). ${ }^{1,2}$ Young adults group (aged $36-45$ years) was the most prevalent in our study, counted for 51 patients $(82.1 \%))^{3,4}$

From a total of 67 samples, IPF groups were analyzed. The results showed that the mean of IPF was 2.41 with a standard deviation of \pm 1.17 in ACS-NSTEMI, 3.1 with a standard deviation of \pm 1.98 in ACS-STEMI, and 1.8 with a standard deviation of \pm 1.46 in UAP. ANOVA test was then performed and showed that there was a significant difference in the value of IPF between groups with $p=0.004$ (Table 2). This result was consistent with Erik et al. study, which showed a significant increase in IPF in ACS patients. Marie et al. in the Netherlands found similar results and stated that IPF could be a more sensitive and specific diagnostic marker than MPV to evaluate platelet turnover in ACS patients. ${ }^{5}$

Erosion, fissure, and rupture of atherosclerotic plaques lead to exposure of the thrombogenic substance to the circulation, causing platelet mobilization to the site. The platelets are then activated and form a platelet plug. Disturbances in

Table 1. Sample characteristics

\begin{tabular}{llcc}
\hline Variable & & $\mathbf{n = 6 7}$ & Percentage (\%) \\
\hline \multirow{2}{*}{ Sex } & Male & 49 & 73.1 \\
& Female & 18 & 26.9 \\
\multirow{2}{*}{ Age } & Young adults & 51 & 82.1 \\
& Older adults & 16 & 17.9 \\
& NSTEMI & 30 & 44.8 \\
\multirow{2}{*}{ Outcome coronary syndrome } & STEMI & 30 & 44.8 \\
& UAP & 7 & 10.4 \\
& Death & 7 & 10.4 \\
& Survive & 60 & 89.6 \\
\hline
\end{tabular}

Table 2. Analysis of IPF in ACS

\begin{tabular}{lccccc}
\hline & N & Min & Max & Mean \pm SD & $\mathbf{p}^{*}$ \\
\hline NSTEMI & 30 & 0.8 & 4.7 & $2.41 \pm 1.17$ & \\
STEMI & 30 & 0.8 & 8.5 & $3.1 \pm 1.98$ & 0.004 \\
UAP & 7 & 0.7 & 4.6 & $1.8 \pm 1.46$ & \\
\hline
\end{tabular}

*ANOVA test 
atherosclerotic plaque along with the effect of activated platelets will subsequently initiate vascular constriction and the coagulation cascade. This process leads to the formation of thrombus. ${ }^{6.9}$

Immature platelet fraction is associated with the progression of coronary heart disease. Immature platelets have a larger volume and are more active than small platelets. These platelets have a greater prothrombotic potential, aggregate more rapidly with collagen and have higher intracellular A2 thromboxane levels. These factors will affect hemostasis potential of platelet that may contribute to the formation of thrombus. Total occlusion in STEMI reflects a greater thrombus due to platelet activation and turnover., ${ }^{5,10-15}$

From a total of 67 samples, MPV values in three ACS groups were analyzed. The results showed that the mean of MPV was 10.59 with a standard deviation of \pm 0.81 in ACS-NSTEMI, 9.9 with a standard deviation of \pm 0.74 in ACS-STEMI, 9.43 with a standard deviation of \pm 0.76 in UAP. ANOVA test was then performed and showed that there was no significant difference in MPV values between the three ACS groups (Table 3).

Mean platelet volume is an average platelet size that reflects platelet activation. The majority of ACS cases occur because of atherosclerotic plaque rupture. This ruptured plaque mostly only occludes less than $50 \%$ of the lumen diameter. After the rupture and endothelial erosion, the subendothelial matrix will be exposed to the circulation. It leads to platelet adhesion followed by platelet activation and aggregation, which results in thrombus formation. The increased consumption of platelets at the site of atherosclerotic plaque results in the release of less mature platelets which are larger in size to the circulation. $^{23,6,8}$

Table 4. Correlation of IPF and MPV in ACS

\begin{tabular}{cc}
\hline & MPV \\
\hline IPF & $r^{*}=0,388$ \\
& $\mathrm{p}^{*}<0,02$ \\
& $\mathrm{n}=67$ \\
\hline
\end{tabular}

*Pearson correlation test

In this study, we also analyzed the correlation between IPF and MPV in ACS patients. Pearson correlation test was performed to assess whether there was a correlation between MPV and IPF. The results showed a positive correlation with $p<0.02$, but the correlation was weak with $r=0.388$ (Table 4). This study was consistent with Mette et al. study in the Netherlands. The correlation of MPV and IPF in ACS patients was based on platelet activation and turnover which cause both values to increase proportionally. ${ }^{3}$

From a total of 67 samples, patients were divided into three groups based on GRACE score and IPF between the three groups was analyzed. The results showed that the mean of IPF was 2.6 with the standard deviation of \pm 1.18 in the score $<100$ groups, 3.12 with standard deviation \pm 2.0 in the score 101-170 group, and 1.73 with a standard deviation of \pm 1.34 in the score $\geq 171$ groups. ANOVA test was then performed, and the test result showed that there was a significant difference in IPF between the three groups with $p=0.005$ (Table 5). The results were consistent with Jose et al. study in the United

Table 3. Analysis of MPV in ACS

\begin{tabular}{lccccc}
\hline & N & Min & Max & Mean \pm SD & $\mathbf{p}^{*}$ \\
\hline NSTEMI & 30 & 9 & 12.6 & $10.59 \pm 0.81$ & 0.01 \\
STEMI & 30 & 8.9 & 11.5 & $9.9 \pm 0.74$ & 0.351 \\
UAP & 7 & 8.5 & 10.6 & $9.43 \pm 0.76$ & 0.02 \\
\hline
\end{tabular}

*ANOVA test, Post Hoc Tamhane

STEMI vs. NSTEMI $p=0.01 ;$ STEMI vs. UAP $p=0.351 ;$ NSTEMI vs. UAP $p=0.02$

Table 5. Analysis of IPF based on GRACE score

\begin{tabular}{lccccc}
\hline & N & Min & Max & Mean \pm SD & p $^{*}$ \\
\hline$\leq 100$ & 27 & 0.8 & 4.8 & $2.6 \pm 1.18$ & \\
$101-170$ & 26 & 0.8 & 8.5 & $3.12 \pm 2.0$ & 0.005 \\
$\geq 171$ & 7 & 0.8 & 4.7 & $1.73 \pm 1.34$ & \\
\hline
\end{tabular}

*ANOVA test 
Table 6. Analysis of MPV based on GRACE score

\begin{tabular}{lccccc}
\hline & N & Min & Max & Mean \pm SD & p $^{*}$ \\
\hline$\leq 100$ & 27 & 8.9 & 11.5 & $10.19 \pm 0.69$ & \\
$101-170$ & 26 & 8.9 & 11.9 & $10.19 \pm 0.84$ & 0.13 \\
$\geq 171$ & 7 & 9 & 12.6 & $10.87 \pm 1.18$ & \\
\hline
\end{tabular}

${ }^{*}$ ANOVA test

States showing that an increase of IPF within 24 hours is associated with poor prognosis, in spite of the GRACE score and normal cardiac biomarkers. ${ }^{6}$

Increased immature platelets are associated with arterial thrombosis, and recent studies have shown that immature platelets are independent predictors in ACS patients receiving antiplatelet therapy and may be used for risk stratification in ACS. A study conducted by Jiminez et al. showed that increased IPF in the first 24 hours was associated with poor prognosis even in patients whose GRACE score was not considered high-risk. ${ }^{5,10,11,15}$

From a total of 67 samples, MPV between the three groups based on GRACE score was analyzed. The results showed that the mean of MPV was 10.19 with the standard deviation of \pm 0.69 in the score $<100$ groups, 10.19 with standard deviation \pm 0.84 in the score 101-170 group, and 10.87 with a standard deviation of \pm 1.18 in the score $\geq 171$ groups. ANOVA test was then performed, and the test result showed that there was no significant difference in MPV between the three groups with $p=0.13$ (Table 6). These results were consistent with Sukmawaty study in Makassar, showing that MPV cannot be used as a prognostic marker for ACS patients. The mechanism of MPV association with the prognosis of ACS patients is unclear. ${ }^{14,15}$

\section{CONCLUSION AND SUGGESTION}

From the results of this study, it can be concluded the increase in MPV and IPF in ACS patients. Immature platelet fraction can be used for risk stratification of ACS patient replacing GRACE score. Mean platelet volume can not to be used as prognostic markers for ACS patient. There is a weak positive correlation between IPF and MPV in ACS patient. Suggestion for subsequent research by looking at cardiac enzymes that are often checked by clinicians when patient is first admitted to the hospital.

\section{REFERENCES}

1. PERKI. Pedoman tatalaksana sindrom koroner. JAKARTA, PERKI, 2015; 1-10.
2. Chang TD, Navarta DA, Monteros A, Trejo G, Baglioni F, Murua $T$, et al. Mean platelet volume as prognostic marker in patients with acute coronary syndrome. Rev Argent Cardiol, 2015; 83: 292-8.

3. Grove LE, Hvas AM, Kristensen SD, Maree AQ, Fitzgerald DJ, et al. Immature platelets in patients with acute coronary syndromes. Cardiovascular. Journal of Denmark, 2009; 08(3): 181-186.

4. Jose R, Endler G, Lalouscheck W, Turfan M, Erdogan E, et al. Mean platelet volume; A potential biomarker of the risk and prognosis of heart disease. Journal of Polandia, 2016; 31, 1009-1017.

5. Hoffmann JJML, Grace RF, Brown T, Michelson AD, Stratz C, et al. Reticulated platelets: A analytical aspects and clinical utility. Clin Chem Lan Med, 2014; 52(8): 1107-1117.

6. Mumpuni R, Manjula R, Rema Pai, Hasim Ahamed, Henry RA, et al. Platelet, and acute coronary syndrome. Journal Form Med; 2016; 41(9): 2380-2658.

7. Hoffbrand AV, Petit JE, Moss PAH. Platelet, blood coagulation, and haemostasis. In: Essential haematology I A.V. $7^{\text {th }}$ Ed., English, Blackwell Publishing, 2016; 265-277.

8. Dacie JV, Lewis SM. Platelet morphology. In: Practical haematology. $10^{\text {th }}$ Ed., English, Churchill Livingstone, 2010; 191-193.

9. Sysmex. Understanding your IPF value. Sysmex xtra online. Accessed at http://sysmex.com. 2016; 1-2.

10. Rosa $A$, Jose R. Immature platelet fraction: A New prognostic marker in acute coronary syndrome. J.Spain, 2013; 66(2); 145-154.

11. Torry S, Panda L, Ongkowijaya J. Gambaran faktor risiko penderita sindrom koroner akut, Bagian Ilmu Penyakit Dalam FK Unstrat, ejournal.unstrat.ac.id, 2014; 1-10.

12. Kurniawan LB, Bahrun U, Rauf D, Arif M. Analisis kaitan jumlah trombosit dengan mortalitas pasien infark miokard akut selama perawatan. Cermin Dunia Kedokteran, 2014; 41(09): 647-649.

13. Loo B, Marin JF. A role for changes in platelet production in the cause of acute coronary syndromes. Arteriosclerosis Thrombosis Vascular Biology. 1998; 672-676.

14. Sukmawaty. MPV: Penanda prognostik pada pasien SKA. Available at www.kalbemed.com/portals/ 6/1_05_18 Mean platelet volume. Accessed onAgustus $14^{\text {th }}, 2017$.

15. Grove EL, Hvas AM, Kristensen, Erik Lerkevang, Mortensen SB, et al. Immature platelet fraction in patients after acute coronary syndrome. Journal of Clinical \& Laboratory Investigation, 2009; 101(1): 151-6. 